\title{
Spot the Difference!
}

\section{Plagiarism identification in the visual arts}

\author{
Leigh Garrett \\ University for the Creative Arts \\ Falkner Road \\ Farnham \\ GU9 7DS \\ lgarrett@ucreative.ac.uk
}

\author{
Amy Robinson \\ University for the Creative Arts \\ Falkner Road \\ Farnham \\ GU9 7DS \\ arobinson@ucreative.ac.uk
}

\begin{abstract}
Over recent years there has been considerable investment in the use of technology to identify sources of text-based plagiarism in universities. However, students of the visual arts are also required to complete numerous pieces of visual submissions for assessment, and yet very little similar work has been undertaken in the area of non-text based plagiarism detection. The Spot the Difference! project (2011-2012), funded by JISC and led by the University for the Creative Arts, seeks to address this gap by piloting the use of visual search tools developed by the University of Surrey and testing their application to support learning and teaching in the arts and specifically to the identification of visual plagiarism. Given that most commonly used search technologies rely on text, the identification and evidencing of visual plagiarism is often left to the knowledge and experience of academic staff, which can potentially result in inconsistency of detection, approach, policies and practices. This paper outlines the work of the project team, who sought to investigate the nature, scope and extent of visual plagiarism in the arts education sector. It will also introduce the iTrace visual searching pilot, developed through the project.
\end{abstract}

Copyright. Images. Information Literacy. Learning. Online Submission. Plagiarism. Referencing. Visual Searchin

\section{INTRODUCTION}

Over recent years there has been considerable interest, investment, and engagement within the higher education sector in the use of digital technology to identify sources of text-based plagiarism. As a result, services such as Turnitin and SafeAssign have been widely adopted across the UK higher education sector to support learning and teaching and to help identify incidents of possible plagiarism in student submissions (iParadigms; Blackboard Inc). Such services allow students and academic staff to upload pieces of written work, which are then checked against a database of journal articles, cached webpages, and previous submitted assignments, to produce a report indicating any matches in the uploaded submission. However, whilst students of the visual arts are required to complete numerous pieces of both visual and text-based submissions for assessment, very little research and development has been undertaken in the identification and detection of suspected cases of visual plagiarism.
The Spot the Difference! project sought to address this gap. The project was led by the Visual Arts Data Service (VADS), a research centre of the University for the Creative Arts, in partnership with the Centre for Vision, Speech and Signal Processing (CVSSP) at the University of Surrey, and was supported with funding from a JISC Learning and Teaching Innovation Grant (June 2011 to May 2012). The project set out with two principal objectives: firstly, to investigate the nature, scope and extent of visual plagiarism in the higher arts education sector; and secondly, to pilot the application of visual search technologies developed by the CVSSP to the issue of visual plagiarism. Feedback on the pilot visual search tool (named iTrace) was then gathered through a series of workshops held at a number of specialist arts institutions, including: the Arts University College at Bournemouth; University College Falmouth; and the University of the Arts London.

This paper presents the findings of the first stage of the project: to investigate the nature, scope, and extent of visual plagiarism in learning and teaching in the arts. The project team will also present a 
demonstration of the outcome of the second stage of the project at EVA 2012: iTrace, the pilot service.

\section{METHODOLOGY}

To appreciate the nature, scope, and extent of visual plagiarism across the UK visual arts higher education arts community, the project team adopted three approaches. Firstly, a systematic review of current literature and guidance within the field was undertaken. Secondly, the team sought to elicit and understand the views, practices, and experiences of academic and professional support staff across the UK arts education sector around the notion of visual plagiarism. This was undertaken by means of an online survey which was followed up with a series of face-to-face, telephone, and Skype interviews with a selection of respondents to explore the issues in much greater detail. Thirdly, by developing, and subsequently testing the iTrace visual plagiarism identification pilot with three specialist arts institutions; recording feedback and revising the pilot service within the scope and resources of the project.

\section{LITERATURE REVIEW}

\subsection{Plagiarism in Higher Education}

Over recent years the higher education sector has become increasingly aware of and anxious about the apparent increasing incidence of plagiarism (Chester 2001, McDowell \& Brown 2001, Furredi 2003, Johnston 2003, Park 2003). While not a new phenomenon, the apparent increase in plagiarism is often considered to be the result of the increasing use and growth of the Internet (Dordoy 2002, McKeever 2006).

However, other commentators have identified alternative possible causes resulting from changes to practices within the higher education sector such as the "massification" of education provision, increased use of coursework in assessment and the importance of grades and increased competition (McDowell and Brown 2001, Dordoy 2002); the failure to ensure students have fully grasped the concepts of plagiarism and academic integrity (Stefani and Carroll 2001, BBC 2004, Bennett 2005, Brown et al 2008); and the failure of institutions to detect and deter plagiarism effectively (Furedi 2004, Sharman and Wilshire 2007).

While there seems little doubt that technology, through the Internet, has facilitated greater access to information and ideas and as many argue provided greater opportunities to plagiarise (Warn 2006), it has also provided the higher education sector with tools to identity and detect plagiarism more systematically. Research also indicates that, if used appropriately, tools for text-based plagiarism detection can also be used formatively to support and develop student and staff understanding of academic practice and develop their research and academic writing skills (McKeever 2006).

\subsection{The Semantic Gap}

However, such tools focus purely on the identification of text-based sources of plagiarism, which is easier to address (Porter 2009). The 'semantic gap' between low-level pixel data within digital images and the complex meanings and descriptions that can be interpreted from an image, makes the visual retrieval and matching of visual resources using technology inherently difficult (Bowman 2008).

\subsection{Learning through Copying}

The practice based nature of the visual arts is distinctive within the higher education sector and further adds to the enormous technological challenges presented by the nature of visual resources themselves.

Copying is a fundamental part of the creative learning process, for example, fashion students could, potentially, be given an assignment to create supplementary items that would fit within existing product ranges, and fine arts students may learn new techniques through sketching in galleries and copying the works of existing artists (Porter 2010a, Porter 2010b).

\subsection{Appropriation}

In addition, the artistic practices of appropriation, homage and pastiche represent a "grey zone", which "encompasses a wide range of acceptable, accepted, and indeed essential practices which if adopted within text-based academic disciplines could be considered as plagiarism" (Kleiman 2010). These practices involve copying elements or using the whole of an existing object or artwork in a new artwork, perhaps to 'send-up', 'build-upon', 'critique' or 'pay tribute' to existing artworks.

These artistic practices have a long history, ranging for example, from the found objects of Marcel Duchamp, to the re-photographic works of Sherrie Levine and Richard Prince, to the more recent graffiti art of Shephard Fairey and Banksy (Tate Glossary). However, they can be particularly troublesome when considering what constitutes plagiarism in an academic context, and within a legal framework given the potential for infringement of intellectual property rights (Bowman 2008).

\subsection{Originality}


Taken to its logical conclusion, it is possible to argue that there is nothing that can be seen to be completely original within the visual arts, and subsequent works are always predicated or built upon the previous work of others and new concepts, ideas, and methods always emerge out of the re-use and repurposing of the past (Crace 2007; Porter 2010a).

\subsection{Visual Referencing}

What's more, like a quote in an essay, the re-use or 'referencing' of original sources in the visual arts could be considered as a positive exercise, indicating a breadth of reading and understanding of the wider context in which a submission is created (Porter 2010a). It is also noted that there may be no arena for referencing and acknowledging sources in the traditional bibliographic sense, for example, as within interior design (Blythman et al 2007).

\subsection{Cultural Differences}

Different practices have also emerged internationally, culturally and commercially within the visual arts which are often at odds with UK academic practice, for example, the process of 'copycatting' which is often observed and documented within the fashion industry, and students who travel to China, might well see photographic, fashion, and design copies sold openly (Blythman et al 2007; Porter 2009). Within higher education it is therefore recommended that the boundaries must be clearly established in project briefs, and the degree of originality required should be made explicit, which will vary both between and within courses (Porter 2009).

\subsection{Learning Activities}

Various learning activities have been developed and adopted in the higher arts education sector to ensure students understand and avoid visual plagiarism (Blythman et al 2007; Vinton and Wareing 2011; Academy of Art University 2010). These activities recognise and appreciate the nature of the 'grey area', and explore the subtleties, complexities, and contradictions that coexist in practice within the visual arts (Kleiman 2010). As such, adopting a preventive and formative approach is seen as the most effective method of tackling plagiarism in the arts (Clements 2010).

These activities could include, for example, asking students to debate and reflect on acceptable practice by looking at the winners of the Plagiarius Awards, an annual negative award that is made to the most blatant design imitations, as well as inviting librarians into the studio to lead sessions on effective research methodologies and citation
(Academy of Art University 2010; Aktion Plagiarius).

\subsection{Developmental Nature}

In addition, the developmental nature of learning and teaching in the arts is seen to minimise the incidence of visual plagiarism. The crit and tutorial enable academic staff to feedback on student work and provide guidance throughout the creative process, and sketchbooks, logbooks, and ongoing drafts are often required for students to document ideas and visual sources (Porter 2010a; Porter 2010b). Students may also be requested to submit a personal statement alongside an assignment outlining the development of their ideas, and if teaching online, students could also be required to submit a photograph of themselves holding their work (Academy of Art University 2010).

\subsection{Accidental Plagiarism}

It has been observed that most incidents of plagiarism are unintentional. This is generally considered to be the result of a lack of understanding and poor academic practice, and most likely to occur amongst students who are just embarking on their academic careers (Porter 2010b).

\subsection{Extent of Visual Plagiarism}

It is considered that visual plagiarism is not as prevalent as its text based equivalent (Blythman et al 2007). However it is noted that there is an increasing number of students across the higher education sector using images to support their academic practice and therefore the issue of image referencing and academic integrity in a visual context could exist far beyond the arts (Blythman and Porter 2008, Porter 2010a, Porter 2010b).

Conversely, student submissions can also be exploited, and several incidents have been reported where ideas have been taken from student degree shows and coursework and have been utilised without permission within the commercial sector (Crace 2007, youthoughtwewouldntnotice.com).

\subsection{Intellectual Property Rights (IPR)}

As mentioned, there may also be legal and IPR implications if students are making use of existing works, particularly since student work in the art and design disciplines is more likely to be shown publically, for example, in exhibitions, student portfolios, and university websites and publications. This is further complicated by the "interwoven matrix of rights" whereby multiple contributors to an item can claim intellectual property, for example, an 
image may be free of copyright but a trademark visible within it may continue to be valid (Porter 2010b).

\subsection{Detection}

It is noted that whilst visual memory might make incidents of visual plagiarism easier to detect, it can be extremely difficult to identify the originating source (Porter 2010a). This has been compounded in recent years by the ever increasing volume of seemingly usable digital visual resources available and by the increasingly sophisticated but simple to use tools for copying, manipulating and representing such resources (Bowman 2008).

\subsection{Technology}

Whilst visual search tools are available such as Tineye, which was presented at the International Plagiarism Conference in 2010, and Google's 'Search by Image' feature (launched during the course of this project), their application to the issue of visual plagiarism is still largely untested and none of the literature reported any systematic use being made of these technologies within the higher education sector.

\section{DATA COLLECTION}

\subsection{Survey and Interviews}

The literature review was followed by the primary data collection exercise in August 2011. This was by means of an online survey directed at academic and professional support staff, the latter included library, learning technology and learning support staff as well as senior managers and leaders drawn from specialist arts universities and colleges and from art and design departments in multidisciplinary institutions within the UK.

The survey was promoted by email to relevant JISCmail lists including the list for the Art, Design, and Media Higher Education Academy as well as a number of other creative arts related lists, and the survey was also publicised with existing contacts and networks. The survey was also disseminated through the dedicated project blog (VADS 2011).

The survey included 27 questions divided into 8 sections covering the definition, identification, incidents, prevention, detection and methods of addressing suspected cases of visual plagiarism, as well as the use of technical tools in this area, and also requested basic details about the respondents such as their roles, type of institution, and subject specialism, and it also offered them the opportunity to make further comments and follow up specific points on the topic of visual plagiarism. Any personal data that was received was treated in confidence and respondents also had the option to answer the survey anonymously.

Responses were supplemented by face-to-face, Skype, and telephone interviews with 8 members of staff from across 4 specialist arts institutions, drawn from both academic and professional support staff, to explore the topic in greater depth.

\subsection{The iTrace Pilot}

The survey also offered the project team the opportunity to explore the requirements of the visual plagiarism pilot service: iTrace as it became known. Respondents were invited to consider their current practices and report on the use of any existing tools; and then to consider: the potential objectives and uses for a pilot detection service; the priorities for such a service; and finally asked them to reflect upon the potential limitations of such a service.

Following the survey, and specification, commissioning and development, the iTrace service (see Figure 1 below) was piloted with groups of staff and students at three specialist arts institutions in January and February 2012. The groups varied in size from 8 to 24 participants and included a mixture of academic, senior management, professional support (including representatives from the library, learning support and learning technology) and students. A full range of higher education experience and disciplinary expertise was also represented across the pilot groups, from graphic design to performing arts, and from textiles to photography. A demonstration was also held at the Annual Learning and Teaching Conference of the University for the Creative Arts in January 2012.

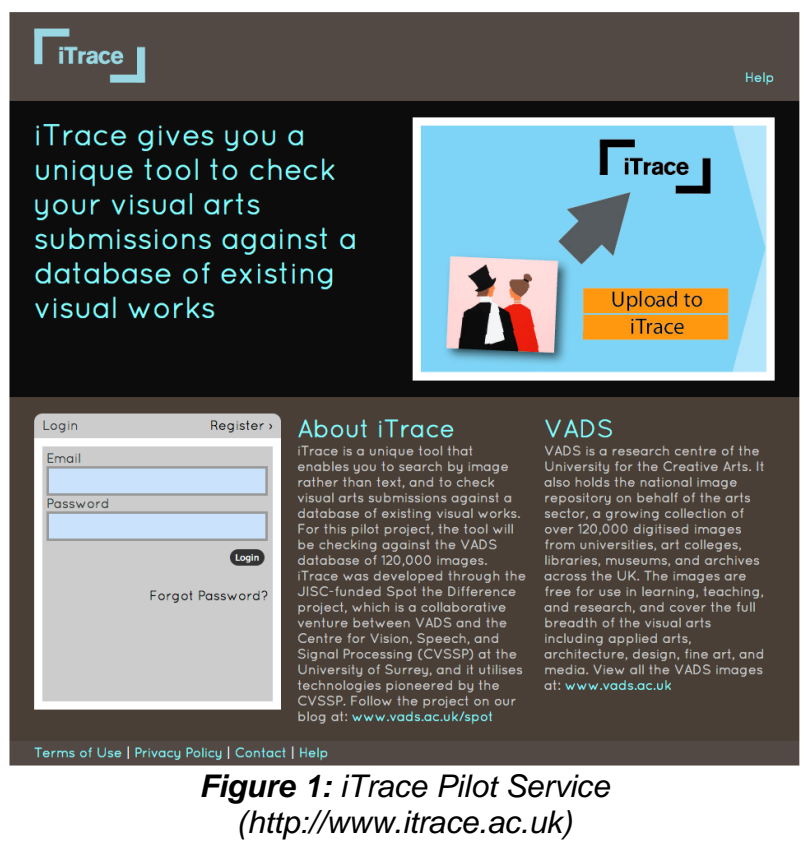


Further feedback was collected throughout the workshops themselves and by means of an online survey which could be completed at the end of, or after, the workshop. Following which, the project team, identified a number of potential areas for development both within the scope and resources of the existing project and for future development.

\section{FINDINGS}

\subsection{Respondents}

A total of 158 respondents took part in the survey. Academic staff comprised the majority of the survey respondents (105 out of a total of the 158 respondents). Other job roles represented include library staff (37 respondents); learning support staff (7 respondents); senior management and executive staff (5 respondents); and learning technologists (1 respondent). 9 respondents selected the 'other' category, these included: a career services manager; cataloguer; external examiner; practicing visual artist; projects officer; a recent MA student; technician; and two curators. Several respondents indicated that they had more than one job function.

The survey was targeted at UK based institutions but the online nature of the survey also caught the attention of 3 international respondents from the visual arts education sector in Canada and India.

Over half of respondents worked within the creative arts in a multidisciplinary institution (57\%); a third were employed in a specialist creative arts institution (32\%); and the remaining respondents worked in more than one university or college (8\%); with a small number (3\%) coming from other backgrounds, including disciplinary areas outside the visual arts, and from the cultural and public sectors.

Most of the respondents taught or supported undergraduate courses (133 respondents); a large number taught or supported postgraduate taught courses (95 respondents); and a smaller number worked with postgraduate research students (52 respondents) and pre-degree courses (47 respondents). The subject areas which were taught or supported by respondents covered the full breadth of the visual arts, as indicated in Table 1.

\subsection{Visual Plagiarism}

\subsubsection{Nature}

Respondents acknowledged that visual plagiarism is generally recognised as the practice of passing off a piece of work as original with the intention to deceive or for whatever reason, unintentionally, failing to acknowledge an original source. One respondent referred to the practice as "Wilfully making use of others' visual material in an

Table 1: Distribution of Respondents by Subject Area

\begin{tabular}{|c|c|c|}
\hline Advertising\# & Illustration & 38 \\
\hline Animation19 & Interior Design & 21 \\
\hline Architecture27 & Jewellery & 12 \\
\hline $\begin{array}{l}\text { Art History and } \\
\text { Theory23 }\end{array}$ & Journalism & 13 \\
\hline Ceramics54 & Metalwork & 6 \\
\hline $\begin{array}{c}\text { Digital } \\
\text { Design11 }\end{array}$ & Marketing & 13 \\
\hline Fashion46 & Photography & 61 \\
\hline Film32 & Printmaking & 31 \\
\hline Fine Art39 & Product Design & 25 \\
\hline Glass48 & Textiles & 30 \\
\hline $\begin{array}{l}\text { Graphic } \\
\text { Design5 }\end{array}$ & $\begin{array}{r}\text { Support multiple } \\
\text { areas }\end{array}$ & 11 \\
\hline 47 & Other & 23 \\
\hline
\end{tabular}

unacknowledged fashion and attempting to pass it off as original work."; while others took a wider view, "I define visual plagiarism as someone using someone's work and/or concepts without giving them credit or asking their permission."; "appropriating an artist's/creator's specific piece of work without acknowledging this provenance, or denying so."; and "visual plagiarism copies but fails to reflect on, or acknowledge, the influence, or significance, of the source."

Interestingly, a very small number of respondents made reference to acceptable and qualifiable changes required to make a piece of work original, one respondent defined plagiarism as "a direct copy of another work or $80 \%$ copy with little adaption", another as "you can use other artists work for inspiration but must change the idea to make it your own at least 6 times."; and "the uncredited appropriation of another artist's work where more than $50 \%$ of the student's work is the same as an established artist's work."

Some respondents did refer to the complexities between plagiarism and the artistic practices of appropriation, parody and pastiche. One stated that the "re-appropriation of existing work is a predominant feature of post modernism...", another, "I think this is a very debatable area to get 
into as it depends upon definitions and contexts around the concept of originality. Students may find it beneficial to practice by repetition of certain styles or genres or even particular artists works, and this can be an invaluable learning strategy.", another, "...'borrowing' the work of others is an accepted art practice (appropriation, recycling) and has a long history in art and photography."

\subsubsection{Extent}

Regarding the extent of visual plagiarism, the survey revealed that $6 \%$ of respondents had seen incidents of visual plagiarism frequently; $42 \%$ reported a lack of referencing for visual materials within written submissions; and $46 \%$ indicated a lack of referencing for visual materials within presentations.

Respondents did note a couple of factors which may indicate that the extent of visual plagiarism remains largely concealed. Several referred to the lack of knowledge, understanding and example of the requirements on the part of academic staff; one even commented that, "a number of my colleagues do not take visual plagiarism seriously.", another "staff often don't reference their visual sources in their teaching presentations and therefore students don't see the importance of doing so." While others noted the lack of institutional guidance and policies, one mentioned that their institution was unwilling to pursue appropriate sanctions due to the potential negative effect on student fees. It was also acknowledged by a number of respondents that it was almost impossible to keep pace with all visual resources and that often they were dependent on their own memory and that of their colleagues.

Overall, the majority of respondents expressed the opinion that incidents of visual plagiarism were rare, largely due to the interactive nature and methods adopted by learning and teaching in the visual arts, with several commenting: "we see very little visual plagiarism because we expect high quality printed portfolios to be handed in for assessment"; "students also show development of their ideas and technique in workbooks."; and "regular tutorials ensures that I can see students' work develop."

\subsubsection{Causes}

Respondents identified various causes of visual plagiarism. The most commonly cited, and more prevalent early on in the academic careers of students and with international students, is lack of understanding of referencing requirements and appropriate guidance. One noted that, "this may just occur at pre-degree level but often students cite 'google' as their source without understanding the distinction between where they found the idea and where the idea actually comes from."
Regarding students themselves, respondents referred to the lack of creative ability, insecurity in own abilities and lack of commitment to study. One respondent referred to a deliberate intention to deceive, a "belief that they will not be discovered...". Mention was also made of institutional factors, including: the "lack of clarity and lack of regulations"; insufficient staff guidance and supervision"; and the, "poor example given by academic staff."

\subsubsection{Learning and Teaching}

Prevention is the favoured approach amongst respondents, one commented, "focus on teaching students what they need to know rather than policing." As a result, a number of practices have emerged within the studio to support learning and teaching. Some respondents indicated that they invited learning support staff and careers advisers into the studio to discuss with students the issues of intellectual property, visual plagiarism and copyright. Others referred students to online resources or study skills workshops run by professional support staff. Several respondents recognised the need for students, as potential practitioners, to appreciate the legal implications of copyright infringement and protection of their own intellectual property. Others discuss with students or presented on the issues regularly within their courses to raise awareness and understanding of referencing, plagiarism and copyright and to embed good academic practice, one noted that, "I run a brief that requires students to research and write about visual plagiarism, copyright, notes of homage etc. in this way they are introduced to nuances of copying and also the laws relating to copyright."

In addition respondents acknowledged that the tutorial system and studio approach to learning and teaching in the visual arts did enable them to actively monitor the creative processes and development of their students. However, one made mention of the fact that this could be challenged by the lack of attendance by some students.

Another approach which respondents referred to was teaching by example and demonstrating best practice within the studio, in order to embed such practice amongst their students. This was reinforced by ensuring visual resources were referenced appropriately and by keeping up to date with contemporary practice.

Although experience appeared limited, a small number of respondents had, or were intending to use a text based plagiarism service to support student practice with written submissions.

Conversely, respondents occasionally expressed concern that some colleagues did not appear to 
take visual plagiarism seriously. One respondent noted that, "Visual plagiarism cannot be avoided. Our society encourages visual plagiarism and we have a long and healthy tradition of plagiarism....". The practice based nature of the visual arts does appear to have an impact upon learning and teaching - one respondent noted that referencing is not a requirement in the commercial sector.

\subsubsection{Identification}

Respondents indicated that the identification and subsequent accusation of plagiarism can be extremely difficult to make for a number of reasons. Firstly, artistic practice can complicate the process; secondly, respondents recognised a lack of understanding of and respect for intellectual property; and thirdly, reference was made to the lack of institutional guidance on the issue for both staff and students.

While emphasis clearly lies on prevention and support mechanisms, respondents did indicate that they have used a variety of techniques to identify cases of suspected visual plagiarism. These include: reflecting upon the progression of a student's work to identify sudden and unexplained changes; to question and test the creation process through the tutorial system and crit; and $65 \%$ of respondents stated that they had used technology to identify possible instances of visual plagiarism, with Google and the visual search tool, Tineye, being the most widely cited examples.

\subsubsection{Procedures}

Inconsistency seemed to be prevalent, with significant numbers of respondents identifying various issues including: the lack of institutional policies and procedures; lack of staff time to check possible incidents; and variations in practice between subject areas and colleagues. One respondent commented that even when plagiarism is detected "the institution had no clear policy on how to respond..."

When incidents were encountered, penalties varied with the nature and severity of the incident, and included: withholding the grade for a piece of work; non progression; reduced marks; tutorial support; a requirement to resubmit a piece of work; written warnings; and, in persistent and serious cases, misconduct proceedings.

\subsubsection{Using Technology}

The survey revealed that the majority of respondents felt that a system could be used positively: to support student learning on the issue of plagiarism (55\%); in deterring incidents of plagiarism (64\%); to confirm suspected incidents $(62 \%)$; and to help identify incidents which had not been identified by other means (57\%).
However, when asked to consider the potential that a visual search service might offer the identification and detection of incidents of visual plagiarism, comments were largely doubtful. The first problem that several respondents noted was that student submissions were not digital. Others felt that it could have a negative affect upon the legitimate and appropriate re-use of images and ideas on the creative process itself. Some mentioned that the need to focus on prevention and to ensure that students understand the nature of academic practice rather than to address detection. Others mentioned that such a system would not be necessary if students are provided with the appropriate knowledge and skills of the issue and their subject area.

\section{3. iTrace}

\subsubsection{Workshop Feedback}

Overall, the participants responded favourably to the project and the iTrace pilot service and its potential to support and enhance learning and teaching in the future. The service itself proved responsive; easy to use; visually engaging; and participants enjoyed challenging the service.

Participants also identified a number of potential useful additional applications within learning and teaching, including: using the service to locate the original source of an image when the reference had been lost; enabling staff and students to protect their own intellectual property from future infringement; and, following on from this, enabling them to monitor and measure the impact of their work, and to maximise revenue.

Participants raised concerns about the value of the service if it wasn't extended across the whole of the Internet, or at least significant art focused databases and information sources. Similarly, concern was raised regarding the potential to recognise objects from different perspectives and angles than those held within the iTrace index. Participants also discussed the relevance of the service to objects and the craft based disciplines, for example in textiles and costume design where digitisation is extremely difficult and copying is accepted as a method of learning; and fine art, where appropriation was often necessary. Related to this was concern that if the system did not identify an original source, then students would assume that the re-use of the image would be acceptable. Discussion also focused on the potential for misunderstanding, where the service might be used to define plagiarism rather than as a tool to support academic staff to identify and detect suspected cases.

Regarding the iTrace pilot service itself: participants found that the image results, both in 
terms of the defined search areas and percentage results, were a little confusing; and that the history page needed further consideration and could become confusing with increased uptake of the service. It was ralso ecommended that consideration should also be given to creating provision for drafts to be submitted, without being matched against each other.

\subsubsection{Areas for Development}

While the system proved to be both resilient and timely, capable of processing jpeg image files and successful in identifying many file manipulations, the workshop participants also identified a number of issues and areas for potential development of the pilot service. These included addressing the following problems: significant cropping of images; inconsistent rotation of images; unsuccessful inverting of images; difficulties in adaptation of images; significant recolouring of images; extreme blurring of images; problems with adaptations which involved textural changes and the failure of image enlargements of over $250 \%$; and increasing the number of file formats which the service could process.

Enquiries were also made with regards to the potential to index all images on the Internet and arts related databases to gain the maximum potential from the service.

\section{CONCLUSIONS}

Prevention seemed to be the most effective course of action adopted by respondents. Methods include: ensuring students have the necessary skills and knowledge to appreciate the differences between artistic traditions and plagiarism; monitoring the creative process; and providing appropriate support mechanisms to safeguard good academic practice.

However, indications are that the notion of visual plagiarism remains unclear due to: artistic and commercial practices; the perceived lack of consistency in approach between colleagues, courses and disciplinary areas; and the absence of institutional guidance, policies and procedures. This context simply adds to the complexity facing academic staff when identifying and evidencing suspected incidents of visual plagiarism.

Overall, regarding the project and potential impact of the iTrace pilot service in learning and teaching, the feedback from respondents was favourably, "I think this is a really useful project and potentially very beneficial."; "This issue is not discussed and awareness is limited (in my experience) alongside any systems I believe an awareness campaign for members of staff would be valuable."; and "More education is required and to warn of the hazards to stop this practice - tutors need to hammer it home..." It also offered respondents and participants the opportunity to reflect upon the nature, scope and extent of visual plagiarism; to consider their own practice and explore the potential which visual search technologies may have to offer.

So, can technology be used effectively to support and enhance learning and teaching in the visual arts in a similar way to text based identification services? In simple terms the evidence suggests a positive answer. However, the complexities presented by the nature of visual resources themselves, the artistic and cultural traditions which govern their use, divergent educational and distinct commercial practices within the visual disciplines present interesting challenges to the current emerging nature of visual search technologies. If technology can rise to these challenges, the implications are far reaching, not only for learning and teaching in the visual arts, but also for much wider application across the cultural, heritage and arts sectors.

\section{RECOMMENDATIONS}

The project team has identified a number of technological challenges which, if resolved, could offer considerable potential to enhance learning and teaching in the area of visual plagiarism and academic practice.

In addition, and outside the original purpose of the project, the team has identified a number of potential applications for visual searching technology within learning and teaching. Further work is needed to understand and respond appropriately to these opportunities, including the ability to: locate and reference original sources correctly; provide a system to protect the intellectual property of students and staff from possible infringement; and to track and measure the impact of visual resources.

\section{REFERENCES}

Academy of Art University (2010) Teaching Tip: Refining Your Teaching, Visual Plagiarism. San Francisco: Academy of Art University. http://faculty.academyart.edu/resource/tips/1768.ht ml (retrieved 29 March 2012).

\section{Aktion Plagiarius Plagiarius Awards \\ http://www.plagiarius.com/e_awards_plag2012.htm I (retrieved 2 April 2012).}

BBC News (2004) 'Plagiarist' to sue University. BBC, $27 \quad$ May 2004. 
http://news.bbc.co.uk/1/hi/education/3753065.stm (retrieved 1 April 2012).

Bennett, R. (2005) Factors associated with student plagiarism in a post-1992 University. Assessment \& Evaluation in Higher Education, 30(2), pp.137162.

Blackboard Inc. SafeAssign. http://www.safeassign.com (retrieved 2 April 2012).

Bowman, S. (2008) The Creativity of Plagiarism. Third International Plagiarism Conference, Northumbria University, Newcastle, UK, 23-25 June 2008.

http://www.plagiarismadvice.org/images/stories/old site/media/2008papers/P12\%20Bowman.pdf (retrieved 29 March 2012).

Brown, C., Dickson, R., Humphreys, A., McQuillan, V. and Smears, E. (2008) Promoting academic writing/referencing skills: Outcome of an undergraduate e-learning pilot project. British Journal of Educational Technology, 39(1), pp.140156.

Blythman, M., Orr, S. and Mullin, J. (2007) Reaching A Consensus: Plagiarism in Non-Text Based Media. London College of Communication, University of the Arts London. http://www.arts.ac.uk/induction/sites/default/files/re source/2010/09/plagiarism-non-tesxt-based-mediacasestudy.pdf (retrieved 29 March 2012).

Blythman, M. and Porter, M. (2008) Visual plagiarism: perspectives from two institutions. Third International Plagiarism Conference, Northumbria University, Newcastle, 23-25 June 2008.

http://www.plagiarismadvice.org/images/stories/old _site/media/2008abstract/052_Blythman\%20Porter .pdf (retrieved 29 March 2012).

Chester, G. (2001) Plagiarism Detection and Prevention: Final Report on the JISC Electronic Plagiarism Detection Project. http://www.jisc.ac.uk/media/documents/programme s/plagiarism/plagiarism.pdf (retrieved 1 April 2012).

Clements, M. (2010) Creating a culture of honesty and prevention: textual and visual plagiarism. Fourth International Plagiarism Conference, Northumbria University, Newcastle, 21-23 June 2010.

http://www.plagiarismadvice.org/documents/confer ence2010/025/Tuesday/Breakfast\%20Workshops

$\% 208.45 \mathrm{am} / \mathrm{Mc} \% 20 \mathrm{Clements} \% 20$ Creating $\% 20 \mathrm{a} \%$ 20Culture\%20 of\%20Honesty\%20and\%20Preventio n\%20Textual\%20and\%20Visual\%20Plagiarism\%2 02010\%203.ppt (retrieved 31 March 2012).

Crace, J. (2007) Here's one I ripped off earlier: For art and fashion students - and their tutors - when does inspiration become plagiarism? The Guardian, 23 January 2007. http://www.guardian.co.uk/education/2007/jan/23/hi ghereducation.uk1 (retrieved 31 March 2012).

Dordoy, A. (2002) Cheating and Plagiarism: Staff and Student Perceptions at Northumbria. Proceedings of the Northumbria Conference, July 2002.

Furedi, F. (2003) Shortcut to success. Times Higher Education Supplement, 25 July 2003. http://www.timeshighereducation.co.uk/story.asp?st oryCode $=178278 \&$ sectioncode $=26$ (retrieved 20 March 2012).

Furedi, F. (2004) Cheats are having a field day on campus, The Telegraph, 17 March 2003. http://www.telegraph.co.uk/education/3336246/Che ats-are-having-a-field-day-on-campus.html (retrieved 21 March 2012).

iParadigms Turnitin. http://turnitin.com (retrieved 2 April 2012).

iTrace Pilot Service. http://www.itrace.ac.uk (retrieved 29 March 2012).

Johnston, B, (2003) The concept of plagiarism. The Higher Education Academy. http://78.158.56.101/archive/palatine/files/927.pdf (retrieved 29 March 2012).

Kleiman, P. (2010) Different shades of grey: the arts of plagiarism. Tackling plagiarism through policy and practice workshop, MacDonald Holyrood Hotel, Edinburgh, 19 March 2010. http://www.heacademy.ac.uk/assets/documents/ev ents/jointevents/2010/Abstracts_document.doc (retrieved 28 March 2012).

McDowell, L. \& Brown, S. (2001) Assessing students: Cheating and plagiarism. The Higher Education Academy. http://www.le.ac.uk/teaching/assets/mcdowell_and _brown.pdf (retrieved 28 March 2012).

McKeever, L. (2006) Online plagiarism detection services - saviour or scourge? Assessment \& Evaluation in Higher Education, 31(2), pp. 155-165. http://citeseerx.ist.psu.edu/viewdoc/summary?doi= 10.1.1.115.2010 (retrieved 28 March 2012).

Park, C. (2003) In Other (People's) Words: plagiarism by university students--literature and lessons. Assessment \& Evaluation in Higher Education, 28(5), pp. 471-488.

Porter, M. (2010) A consideration of academic misconduct in the creative disciplines: from inspiration to imitation and acceptable incorporation. EMERGE, 2, pp. 1-16. http://www.northumbria.ac.uk/static/5007/arpdf/132 9815/emergeporter2 (retrieved 1 April 2012).

Porter, M. (2010) Beyond simple textual plagiarism: some probable issues and possible answers. Fourth International Plagiarism Conference, Northumbria University, Newcastle, 21-23 June 
2010.

http://www.plagiarismadvice.org/documents/confer ence2010/papers/4IPC_0034_final.pdf (retrieved 1 April 2012).

Porter, M. (2009) Beyond text based plagiarism: A paradigm for tackling academic misconduct in the creative disciplines (Red Guide). Northumbria University, Newcastle. http://www.northumbria.ac.uk/static/5007/arpdf/aca demy/redguide54.pdf (retrieved 1 April 2012).

Sharman, J. and Wilshire, C. (2007) Review essay: Fighting Plagiarism in Australian Universities: Why

Bother? Australian Journal of Political Science, 42(3), pp. 503-508.

Stefani, L. \& Carroll, J. (2001) A briefing on

plagiarism. LTSN Generic Centre Assessment. www.heacademy.ac.uk/assets/.../id10_Briefing_on _Plagiarism.rtf (retrieved 1 April 2012).
Tate Glossary Appropriation. http://www.tate.org.uk/collections/glossary/definitio n.jsp?entryld=23 (retrieved 2 April 2012).

VADS (2011) Spot the Difference Project

http://www.vads.ac.uk/spot (retrieved 2 April 2012).

Vinton, L. and Wareing, S. (2011) Or is it homage? Preventing and dealing with plagiarism in multidisciplinary contexts. Fifth Institutional Policies and Procedures for Managing Student Plagiarism Event, Oxford Brookes University, Oxford, 9 June 2011.

http://www.brookes.ac.uk/aske/Plagiarism\%202011 /Plagiarism\%202011\%20Waring\&Vinton\%20prese ntation.ppt (retrieved 31 March 2012).

Warn, J. (2006) Plagiarism software: no magic bullet! Higher Education Research \& Development, 25(2), pp. 195-208.

You Thought We Wouldn't Notice. http://youthoughtwewouldntnotice.com/blog3 (retrieved 28 March 2012). 